\title{
A RETOMADA INDÍGENA DOS TERRITÓRIOS DO SABER: THE THUNDERBIRD POEMS, DE ARMAND GARNET RUFFO
}

\author{
RECLAIMING INDIGENOUS KNOWLEDGE: ARMAND GARNET RUFFO'S THE THUNDERBIRD POEMS
}

\section{RESUMO}

Neste artigo, analiso The Thunderbird Poems (2015) de Armand Garnet Ruffo como um ato compartilhado de retomada cultural e territorial, através do qual, como Ruffo afirma em seu ensaio "Why Native literature?" (1997), a literatura indígena se dirige "Aos próprios indígenas a fim de que possam se empoderar e curar através da história real" (p. 143). Ruffo descreve seu trabalho poético como o resultado de uma parceria compartilhada com Norval Morrisseau, já que os poemas surgem após os encontros que teve com o artista, nos quais ouvia sua história de vida incorporada na biografia Norval Morrisseau: Man Changing into Thunderbird (2018). A leitura poética que Ruffo faz do quadro de Morrisseau The Land (1976), que se intitula "The Land (Land Rights)", exemplifica como a parceria entre o artista plástico e o poeta, ambos pertencentes ao povo Anishinaabe, transforma seus trabalhos artísticos em uma performance coletiva de retomada dos saberes indígenas.

Palavras-Chave: Literatura Indígena. Armand Garnet Ruffo. Performance. Saberes Ameríndios.

\section{ABSTRACT}

In this article, I analyze Armand Garnet Ruffo's book The Thunderbird Poems (2015) as a communal act of cultural and territorial redress, in which, as Ruffo states in his essay "Why Native literature?" (1997), Indigenous literature addresses "Native people themselves so that they can empower and heal themselves through the real story" (p. 143). Ruffo describes his poetical work as the result of a communal partnership with Norval Morrisseau, since the poems emerged after his encounters with the artist to listen to his life story, which resulted in the biography Norval Morrisseau: Man Changing into Thunderbird (2018). Ruffo's poetic reading of Morrisseau's painting The Land (1976), which is called “The Land (Land Rights)", exemplifies how the partnership between the Anishinaabe visual artist and the Anishinaabe poet turns their artistic works into a collective performance that reclaims Indigenous knowledge.

Keywords: Indigenous Literature. Armand Garnet Ruffo. Performance. Indigenous Knowledge.

Rubelise da Cunha

Universidade Federal do Rio Grande (FURG) - Brasil. E-mail: rubelisecunha@furg.br 
Like a Buddha he sits at the genesis of consciousness

Embodied as a brilliant thunderbird

Armand Garnet Ruffo

\section{A Gênese}

A ideia para este trabalho surgiu após assistir à apresentação do escritor e crítico literário indígena Armand Garnet Ruffo, professor da cátedra de Literatura Indígena da Queen's University em Kingston, Ontário, no Canadá. No Festival de Literatura Indígena em Orillia, em julho de 2018, Ruffo apresentou alguns de seus poemas do livro The Thunderbird poems (2015) em diálogo com a biografia que escreveu sobre o artista visual Norval Morrisseau, intitulada Norval Morrisseau: Man Changing into Thunderbird (2018). Enquanto lia os poemas e citava trechos da biografia de Morrisseau, o autor projetava imagens dos quadros pintados pelo artista plástico, a partir dos quais seus poemas haviam sido originados.

A performance na qual o crítico literário, o poeta e o biógrafo se tornaram uma única voz para reafirmar a importância de Norval Morrisseau como xamã e artista Ojibway é resultado de sua parceria com Morrisseau, sendo que a biografia e os poemas surgiram após os encontros que Ruffo teve com o artista, nos quais ouvia sua história de vida. A parceria entre o xamã e artista visual e o escritor e acadêmico, ambos da nação indígena Ojibway (o povo Anishinaabe), possibilitou o surgimento de um discurso estratégico de autonomia e autoafirmação, através do qual a prática tradicional de contação de histórias é expressa na pintura, biografia e poesia, culminando com a reinvindicação do conhecimento e da espiritualidade Ojibway no ambiente acadêmico.

\section{Os Saberes Tradicionais}

Uma das marcas da Literatura Indígena nas Américas é seu compromisso com o resgate dos saberes dos povos originários. $\mathrm{O}$ escritor e intelectual indígena procura marcar seu espaço singular na cultura eurocêntrica, pois sua existência hoje se configura no limiar complexo da interculturalidade dos saberes, mas sempre reafirmando seu ponto de partida original e único, advindo da experiência significada pelo "ser indígena". Esta marca existencial está intimamente ligada à noção de pertencimento, expressa na interrelação entre língua, cultura, saberes e território.

No resgate das tradições culturais, reafirma-se que os saberes são construídos coletivamenteatravés da contação de histórias, sendo esses saberes hoje reapresentados em formas artísticas ocidentais a fim de que o gênero literário recupere a performance tradicional (Cunha, 2009). Este conceito de gênero como performance, desenvolvido por John Frow (2005), torna-se estratégico para possibilitar uma visão do literário 
que extrapola os limites do texto escrito e enfatiza o caráter intencional das formas literárias, configurando-se como um ato de fala, característica de uma literatura cujas raízes se encontram na construção coletiva de conhecimento através das práticas narrativas. No intuito de resgatar esse sentido primordial da contação de histórias, a escritora indígena Lee Maracle, pertencente ao povo Salish no Canadá, defende a história (story), e não os gêneros literários ocidentais, como o elemento central para o estudo da literatura indígena. Em suas palavras,

o objetivo para se ouvir (e agora ler) uma história é estuda-la em si mesma e, a partir dela, examinar o contexto em que é contada, entender os obstáculos à existência que apresenta, e então vermos a nós mesmos através da história, ou seja, transformar a nós mesmos de acordo com nossa concordância e entendimento ${ }^{1}$ (2007: 55).

Maracle se alinha com o pensamento da antropóloga Julie Cruikshank, que em The social life of stories: narrative and knowledge in the Yukon territory (1998), aponta o papel fundamental da contação de histórias para a resolução de conflitos, já que quando surge a possibilidade de conflito entre pessoas com perspectivas diversas, uma solução satisfatória geralmente envolve demonstrar como uma história pode reformular uma questão ao providenciar um contexto mais amplo para sua avaliação (p. xv). Essa perspectiva pode ser relacionada com a afirmação de Maracle de que a contação de histórias possui uma função prática, o que valoriza a forma literária enquanto ação, ou seja, um ato de fala que possui uma função social, e é fundamental para a cura e sobrevivência das culturas indígenas (Cunha \& Goldemberg, 2010: 121).

$\mathrm{O}$ posicionamento de Maracle reflete muito do que outros escritores ameríndios também afirmam sobre a Literatura Indígena, fazendo com que sua definição perpasse por uma forte conexão com um dos elementos fundamentais das performances de contação de história tradicionais: a coletividade. Tal elemento é também hoje enfatizado na teoria crítica construída por pensadores indígenas brasileiros, dentro os quais destaco Ailton Krenak. Em sua entrevista a Jailson de Souza Silva, "A Potência do Sujeito Coletivo - Parte I", Krenak conecta o sentido de coletividade à questão da territorialidade. Ao pensar a singularidade do ser "indígena" no contexto brasileiro, Krenak resgata o sentido de origem, e de como se constituem as relações nas sociedades indígenas tradicionais:

Acho que durante muito tempo essas vidas foram experiências invisíveis, de gente maravilhosa que deu conta de criar os filhos, de formar uma comunidade, de proteger um território, de construir um sentimento de territorialidade onde aquele complexo de trocas, de famílias, de camaradagem vai se dando e os meninos crescem nesses ambientes com uma potência, uma capacidade,

1 As traduções das citações dos textos originais em inglês foram feitas pela autora do artigo. 
uma liberdade tão maravilhosa. Esse mundo acaba se constituindo como uma biosfera; lugar onde aquelas vidas chegam há cem anos, até mais, são sábios, pessoas com trajetórias ricas, mas que não conectam com as realidades complexas do mundo global que tomamos consciência mais tarde. (Krenak, 2018: 4)

Krenak enfatiza a conexão com a terra como a conexão com a cultura, a coletividade e o próprio sentido de existência, sinalizando a violência do processo que os retira de seu território para realocá-los em outras esferas socioculturais e territoriais. Sendo assim, a presença indígena em outros espaços é sempre marcada por sua relação com o território de origem deixado forçosamente. Apesar de gerar certa instabilidade e insegurança, há nesta posição intersticial ocupada pelo sujeito indígena um potencial para a construção de novos conhecimentos, os quais são gerados

a partir da reconexão com as tradições, a coletividade indígena e a ancestralidade:

Sacar uma biografia de um ambiente desses é uma maneira de iluminar todo esse ambiente e projetar sentido na vida de todo mundo; nossos avós, tios, pais, dos nossos irmãos, dos colegas de infância. É uma nave. É uma constelação de seres que estão viajando e transitando no mundo, não no da economia e das mercadorias, mas no mundo das vidas mesmo, dos seres que vivem e experimentam constante insegurança. (Krenak, 2018: 5)

Dessa forma, o fazer literário indígena torna-se uma forma de inscrever-se enquanto indígena no espaço dos saberes do outro ocidental. O surgimento de The Thunderbird poems a partir do encontro com Norval Morrisseau e da escrita de sua história de vida evidencia o quanto Ruffo realiza um processo de reinserção de sua biografia autoral enquanto potência coletiva, num exercício de reconexão com seu povo de origem, o povo Anishinaabe (Ojibway), seus territórios e saberes.

\section{Pintura, Poema e História: Uma Performance}

A gênese desta obra poética de Ruffo inicia no momento em que Morrisseau torna-se o primeiro artista plástico indígena a ter uma exposição solo na National Gallery of Canada. Greg Hill, curador e diretor de Arte Indígena na Galeria Nacional, foi o organizador da retrospectiva Norval Morrisseau, Shaman Artist, e convidou Ruffo para que escrevesse algo sobre o artista Ojibway para o catálogo da exposição. $\mathrm{Na}$ introdução à biografia que escreveu sobre Morrisseau, Ruffo relata que aceitou o convite, mas informou que não tinha interesse em escrever um texto jornalístico, e sim queria "contar uma história": "Eu queria utilizar a forma tradicional de aquisição do conhecimento que é central para a cultura Ojibway e para as culturas indígenas em geral. E, o máximo possível, eu queria embasar minha história na epistemologia 
Anishinaabe e no que hoje denominamos história oral" (2018: 3). O encontro de Ruffo e Morrisseau cria um evento no qual o xamã conta suas histórias oralmente, ao mesmo tempo em que conta histórias através da sua arte visual. Ruffo, por sua vez, continua a tradição da contação de histórias ao transformar a história de vida e os quadros de Morrisseau em biografia e poesia.

Através dos encontros entre Ruffo e Morrisseau, a história para o catálogo se transforma em biografia, e o processo de imersão na vida e obra do artista visual Ojibway move o poeta a transformar as imagens em poesia. Em sua entrevista com Liz Howard, ele comenta:

Em relação à minha biografia Norval Morrisseau: Man Changing into Thunderbird, inicialmente pensei que seria completamente em prosa, mas assim que mergulhei em sua vida e arte, notei que poemas começaram a surgir e apenas deixei que eles viessem. Uma torneira havia sido aberta e os poucos poemas na biografia se transformaram em um livro próprio, The Thunderbird poems. Eu descobri no processo que a poesia pode lidar com coisas que a prosa não consegue, ou pelo menos a poesia consegue fazer isso mais sucintamente. Foi então que comecei a pensar na forma de poesia que eu estava escrevendo; tinha de ser baseada no mundo dos Anishinaabek Manidoog ou Manitous. (2018: 33)

The Thunderbird poems (Poemas do Pássaro do Trovão) é uma obra dividida em quatro partes: Life Scroll (Listagem da Vida), Shaman Rider (Andarilho Xamã), Mother of All Things (Mãe de Todas as Coisas) e Indian Canoe (Canoa Indígena). Cada poema corresponde a um dos quadros de Morrisseau, cuja trajetória através da pintura também foi de resgate de suas origens e de desenvolvimento de seu potencial xamânico através da arte. Ao receber Ruffo em sua casa para o início deste processo que culmina com os poemas, Morrisseau indaga ao escritor: "Por que você demorou tanto?”. Neste momento sinaliza que tal encontro estava predestinado como parte da cadeia de transmissão de saberes, manifestos nas obras de Ruffo, que também realiza um movimento de retorno às origens após o encontro com o xamã e artista visual.

A obra poética de Ruffo é exemplar em traduzir a potência do sujeito coletivo de que nos fala Krenak, marcando o forte elo que a liga com o povo Anishinaabe e com a história contada por Morrisseau através de sua arte visual. Um poema emblemático que expressa esta marca do "ser indígena" na obra literária, fazendo sempre a ligação com o pertencimento ao território, é o poema "The Land (Land Rights), 1976", que pode ser traduzido como "A Terra (Direitos Territoriais), 1976". O poema é baseado no quadro de Morrisseau intitulado The land (A terra), de 1976, e ambos abordam o conflito colonial e as ameaças trazidas pelo homem branco aos povos indígenas, aos animais e à natureza. Na primeira estrofe, há a sinalização de que algo no quadro de Morrisseau não é usual, de que sua arte tem um objetivo maior e se recusa a fazer parte do mundo das mercadorias de que nos fala Krenak: 
Este quadro ele não o fez por dinheiro,

Ele provém de algo mais longínquo em sua mente.

Algo diferente

acontece aqui. ${ }^{2}$ (Ruffo, 2015: 50)

O conflito colonial é enfatizado no poema através do subtítulo adicionado pelo poeta - "Land Rights" (Direitos Territoriais), que faz do espaço poético um local de disputa territorial. Ao incorporar também um caráter narrativo e descritivo ao poema, Ruffo sinaliza seu vínculo com as performances de contação de história tradicionais, as quais reformulam um conflito ao proporcionar um contexto mais amplo para avaliá-lo (Cruikshank, 1998). A divisão da tela em dois lados, um referente ao mundo branco e o outro ao mundo indígena, sinaliza a demarcação e o conflito:

Ele começa separando a tela em dois espaços. Dois caminhos parecendo um cinto.

Um lado azul para o oceano.

Um lado vermelho para o pôr-do-sol

Um lado para o Índio

Um lado para o Homem Branco. ${ }^{3}$ (Ruffo, 2015: 50)

Após demarcar o espaço, o poema destaca no quadro elementos importantes da performance das narrativas orais, tais como: o reconhecimento dos ancestrais, que devem ser reverenciados quando o contador de histórias se apresenta ao início da narrativa; o reconhecimento da tradição e da linhagem, representados pelos animais míticos, que fazem partem da constituição de sentido do ser humano; e a continuidade geracional expressa na figura do bebê:

No lado índio, um homem, a geração antiga, está sentado com um bebê chorando em seu colo. Um castor falante balança em sua cabeça como um totem. Embaixo de seus pés pássaros e peixes o sustentam.

2 This painting he doesn't whip up for money.

It's the furthest thing from his mind.

Something else

is going on here.

3 He begins by separating the canvas

into two spaces. Two paths

much like a wampum belt.

One side blue for ocean.

One side red for sunset.

One side for Indian.

One side for Whiteman. 
Todo o mundo natural em seu interior.

Atrás dele, as faces dos ancestrais

de costas para os tratados. ${ }^{4}$ (Ruffo, 2015: 50 )

Ao descrever que os ancestrais estão "de costas para os tratados", o poema narra, de certa forma, a desconfiança por parte da sabedoria ancestral dos tratados assinados pelos colonizadores a fim de demarcar o território indígena, já que a experiência indígena aponta o descumprindo de acordos firmados. Na estrofe seguinte, esta impossibilidade de comunicação e confiança entre os dois mundos é enfatizada nas palavras do ancião: "Olhe eles, o homem está dizendo, Olhe isso,/ mas suas palavras não cruzam a divisória/ e não são ouvidas”' (Ruffo, 2015: 50). A poesia, então, constrói conhecimento sobre o passado colonial, fazendo com que a defesa dos direitos territoriais e a retomada da terra se reconfigure também como um ato simbólico de retomada do território das formas de arte indígenas cujas raízes estão na contação tradicional de histórias.

A presença dos animais míticos também aponta para outro elemento significativo na obra de Ruffo e no quadro de Morrisseau: o resgate da mitologia e da espiritualidade Ojibway. O castor falante que balança na cabeça do ancião "como um totem" insere o caráter mítico cuja temporalidade circular conecta o passado (ancestralidade e o pertencimento Ojibway à terra) à continuidade da vida no futuro (o bebê). É a criança no colo do ancião que resiste e reage à presença dos colonizadores, que são identificados como os "canadenses de faces brancas", sinalizando a identidade canadense como uma alteridade à presença indígena:

A criança ataca os dois canadenses de face branca apavorados com os gritos que saem de sua boca, com o punho que é quase do tamanho de sua cabeça dando socos naquela direção. ${ }^{6}$ (Ruffo, 2015: 50)

Na pintura e no poema, humanos e não humanos reagem à chegada dos canadenses, sinalizando o aspecto panteísta das mitologias indígenas que Tomson

\footnotetext{
4 On the Indian side, a man, the older generation, sits with a howling baby on his lap.

A talking beaver balanced on his head like a totem.

Below his feet birds and fish support him.

The whole natural world inside him.

Behind him, the faces of the ancestors

facing backwards to the treaties.

5 Look at them, the man is saying, Look at this,

but his words do not cross the divide

and go unheard.

6 The child strikes out toward two white-faced Canadians

startled by the cries curling from his mouth,

by his fist nearly the size of his head

punching through to their side.
} 
Highway defende em Comparing Mythologies (2003) em que a natureza, os animais e os humanos coabitam e se relacionam em termos equânimes. Os canadenses, por outro lado, são marcados como aqueles que chegaram depois, os "colonos", e representam uma ameaça à continuidade da vida:

\author{
Os animais também protestam contra a destruição \\ que os colonos trouxeram com eles. \\ Juntos eles dizem quando a terra morre \\ nós todos morremos. Algo que o \\ artista quer que você veja. Claramente, \\ como um copo de água potável.7 (Ruffo, 2015: 51)
}

\title{
A retomada
}

O poema de Ruffo sobre o quadro A terra (1976) de Morrisseau é um ato coletivo de retomada cultural e territorial, o qual referenda a definição de literatura indígena apresentada pelo escritor em seu artigo "Por que literatura indígena?" (1997). Nesse texto, Ruffo defende que a literatura indígena, e também acredito que as artes indígenas em geral, "são voltadas diretamente ao povo indígena a fim de que possam se empoderar e curar através da história real" (p. 143). No encontro entre os dois artistas Ojibway, a cura é processada coletivamente, e a junção das telas pintadas, da história de vida narrada e dos poemas torna-se uma performance artística única de resgate das raízes ancestrais.

Na leitura poética que Ruffo faz do quadro de Morrisseau, ele vê os animais dizerem que "quando a terra morre\ nós todos morremos" (p. 51), reforçando um sentido de existir em estreita conexão com o território. Dessa forma, o poeta identifica Morrisseau como o xamã que sendo homem, transforma-se em entidade mítica, o Pássaro do Trovão, para reivindicar a terra e o conhecimento indígenas em sua arte como forma de sobrevivência, a fim de evitar que a "queda do céu se cumpra", profecia sinalizada por Davi Kopenawa em sua narrativa mítica oriunda da tradição xamânica A queda do céu: palavras de um xamã yanomami (2015). Esta consciência planetária demonstra-se crucial atualmente no Canadá, no Brasil e globalmente, pois enquanto os povos originários reclamam seus territórios e a proteção do meio ambiente, as práticas coloniais de destruição reveladas pelos artistas ainda prevalecem. No entanto, o que a narrativa cíclica recuperada em pintura e poema nos lembra é que a destruição apocalíptica que remetemos ao futuro já esteve presente no passado,

7 The animals too protest the destruction the settlers have brought with them.

Together they are saying when the earth dies

we all die. It is something

the artist wants you to see. Clearly,

like a glass of drinking water. 
descrevendo a chegada do homem branco como um fim de mundo para os povos originários.

O encontro entre Armand Garnet Ruffo e Norval Morrisseau também sinaliza uma trajetória de retorno de Ruffo às suas raízes. Neste encontro com o xamã e artista visual, Ruffo potencializou sua missão como acadêmico, crítico literário, poeta e escritor ao reivindicar um espaço territorial para os povos indígenas e para o conhecimento Ojibway, transformando as formas artísticas e acadêmicas ocidentais num espaço no qual o contador de histórias e o xamã constroem conhecimento e curam com suas palavras numa performance que é visual, espiritual e coletiva. A trajetória de Morrisseau também foi de autocura, e de um renascimento espiritual, descobrindo que sua força xamânica poderia ser traduzida em imagens, e que essas seriam sua forma de interagir no mundo eurocêntrico para que as culturas ancestrais pudessem resistir e continuar. Ruffo encerra o poema do qual origina-se a epígrafe deste texto, intitulado "Astral Thunderbird, 1978", com versos epifânicos, os quais conseguem descrever a força transformadora da arte oriunda da potência do sujeito coletivo:

\author{
E o inacreditável se tornar crível \\ A fé é tudo. \\ Prova num pincel de cor \\ que pode curar ninguém mais \\ do que a si mesmo. ${ }^{8}$ (Ruffo, 2015: 67)
}

\title{
REFERÊNCIAS
}

CRUIKSHANK, Julie. The Social Life of Stories: Narrative and Knowledge in the Yukon Territory. Vancouver: UBC Press, 1998.

CUNHA, Rubelise da. “The Unending Appetite for Stories': Genre Theory, Indigenous Storytelling and Tomson Highway's 'Rez Cycle.” The Canadian Journal of Native Studies XXIX, 1\&2 (2009):165-182.

; GOLDEMBERG, Deborah. Literatura indígena contemporânea: o encontro das formas e dos conteúdos na poesia e prosa do I Sarau das Poéticas Indígenas. Espaço Ameríndio, v. 4, n. 1, 2010, p. 117-148.

HIGHWAY, Tomson. Comparing Mythologies. Ottawa: University of Ottawa Press, 2003.

8 And the unbelievable becomes believable.

Faith is everything.

Proof in a brush of colour

that can heal anyone

but himself. 
KOPENAWA, Davi; ALBERT, Bruce. A queda do céu: palavras de um xamã yanomami. São Paulo: Companhia das Letras, 2015.

KRENAK, Ailton. A Potência do Sujeito Coletivo - Parte I [entrevista concedida a Jailson de Souza Silva]. Revista periferias - O paradigma da potência, p. 1-21, v. 1, n.1, 2018. Disponível em http://revistaperiferias.org/materia/a-potencia-do-sujeitocoletivo-parte-i/. Acesso em 29 de julho de 2019.

MARACLE, Lee. Oratory on Oratory. In: KAMBOURELI, Smaro; MIKI, Roy. Trans. Can.Lit: Resituating the Study of Canadian Literature. Waterloo: Wilfrid Laurier, 2007.

RUFFO, Armand Garnet. "Why Native Literature?" In: Macfarlane, Heather; Ruffo, Armand Garnet. Introduction to Indigenous Literary Criticism in Canada. Peterborough: Broadview Press, 2016. p. 133-144.

. Norval Morrisseau: Man Changing into Thunderbird. Madeira Park: Douglas \& McIntyre, 2018.

. The Thunderbird Poems. Madeira Park: Harbour Publishing, 2015.

; HOWARD, Liz. Our Boreal Roots: Armand Garnet Ruffo and Liz Howard. In: TAYLOR, Rob. What Poets are Doing: Canadian Poets in Conversation. Gibsons: Nightwood, 2018. p. 27-38. 